\title{
Quantitative Approaches to Assess Key Carcinogenic Events of Genotoxic Carcinogens
}

\author{
Shoji Fukushima ${ }^{1,2}$, Min Gi $^{3}$, Masaki Fujioka ${ }^{3}$, Anna Kakehashi ${ }^{3}$, Hideki Wanibuchi ${ }^{3}$ and \\ Michiharu Matsumoto ${ }^{2}$ \\ ${ }^{1}$ Association for Promotion of Research on Risk Assessment, Nakagawa, Nagoya, Japan \\ ${ }^{2}$ Japan Bioassay Research Center, Hadano, Kanagawa, Japan \\ ${ }^{3}$ Department of Molecular Pathology, Osaka City University Graduate School of Medicine, Abeno, Osaka, Japan
}

\begin{abstract}
Chemical carcinogenesis is a multistep process. Genotoxic carcinogens, which are DNA-reactive, induce DNA adduct formation and genetic alterations in target cells, thereby generating mutated cells (initiation). Subsequently, preneoplastic lesions appear through clonal proliferation of the mutated cells and transform into tumors (promotion and progression). Many factors may influence these processes in a dose-dependent manner. Therefore, quantitative analysis plays an important role in studies on the carcinogenic threshold of genotoxic carcinogens. Herein, we present data on the relationship between key carcinogenic events and their deriving point of departure (PoD). Their PoDs were also compared to those of the carcinogenesis pathway. In an experiment, the liver of rats exposed to 2-amino-3,8-dimethylimidazo-(4,5-f)quinoxaline (MeIQx) was examined to determine the formation of MeIQx-DNA adducts, generation of mutations at LacI transgene, and induction of preneoplastic glutathione $S$-transferase placental form (GST-P)-positive foci and tumors (benign and malignant). The PoDs of the above key events in the carcinogenicity of MeIQx were increased as the carcinogenesis advanced; however, these PoDs were lower than those of tumor induction. Thus, the order of key events during tumor induction in the liver was as follows: formation of DNA adducts $<<$ Mutations $<<$ GST-positive foci (preneoplasia) $<<$ Tumor (adenoma and carcinoma). We also obtained similar data on the genotoxic and carcinogenic PoDs of other hepatocarcinogens, such as 2-amino-3,8-dimethylimidazo(4,5-f)quinoline. These results contribute to elucidating the existence of a genotoxic and carcinogenic threshold.
\end{abstract}

Key words: Cancer risk assessment, Point of departure, Linear no-threshold carcinogenicity, Genotoxic carcinogen, MeIQx, IQ

\section{INTRODUCTION}

The linear no-threshold theory (LNT) of carcinogenicity is a hypothesis that originated from studies on radiation carcinogenicity and then expanded to chemical carcinogenicity in regulatory risk assessments. At present, carcinogens are generally classified into two categories: genotoxic and

Correspondence to: Shoji Fukushima, Association for Promotion of Research on Risk Assessment, 134 Arako 1-chome, Nakagawa, Nagoya 454-0869, Japan

E-mail: anhyohken@cloud-line.net

This is an Open-Access article distributed under the terms of the Creative Commons Attribution Non-Commercial License (http:// creativecommons.org/licenses/by-nc/3.0) which permits unrestricted non-commercial use, distribution, and reproduction in any medium, provided the original work is properly cited. nongenotoxic. The no-threshold concept of genotoxic carcinogens, which is accepted in risk assessment, is based on the idea that carcinogenesis is influenced by a single genetic event. However, the pathway of chemical carcinogenesis has been apparent, and it has been accepted that the in vivo biological mechanism exists for both the enhancement and inhibition of carcinogenesis.

Previously, to prove the LNT of genotoxic carcinogens, a low-dose carcinogenicity study on a famous carcinogen, 2-acetylaminofluorene (2-AAF), was conducted in mice. Approximately 20,000 female BALB/cStCrlfC3Hctr mice were fed ad libitum diet containing 2-AAF at 30 to 150 ppm for a maximum of 33 months (the so-called ED01 study) (1). In this lifespan carcinogenic study, the liver and urinary bladder, which are the target organs of 2-AAF, were examined. The data on urinary bladder tumor did not 
contradict the LNT of 2-AAF carcinogenicity, whereas those of liver carcinogenesis supported the LNT. However, we noticed that the lowest dose, $30 \mathrm{ppm}$, was still high to be used in the low-dose carcinogenicity testing of 2-AAF. In another study, Peto et al. (2) investigated the low-dose hepatocarcinogenicity of N-nitrosodiethylamine (DEN) in Colworth rats. DEN at 0.033 to 16.896 ppm was administered to 2040 male and 2040 female rats via drinking water. A linear dose-dependent induction of liver tumors was observed. The absence of threshold for DEN hepatocarcinogenicity was reported. However, it was noted that the lowest DEN dose in this study is still higher than human exposure level to DEN.

In their metabolic pathways, most genotoxic carcinogens are metabolized to their active forms, which are the ultimate carcinogens that bind covalently to DNA, forming carcinogenesis-related adducts. Generally, such DNA adducts are efficiently repaired; however, there is a possibility of misrepair or misreplication of damaged DNA, which may result in the fixation of mutations in the cell genome. These irreversible mutations contribute to the initiation of carcinogenesis. Most mutated cells will die because of metabolic dysfunctions or apoptosis. However, some of them will survive as initiated cells. In the twostage carcinogenesis theory, this sequence of the events is thought to occur during the initiation stage. In the promotion and progression stages, initiated cells proliferate to form preneoplastic lesions and finally develop into tumors (benign at first and then malignant). This pathway is generally accepted as the mode of action of genotoxic carcinogens.

Long-term carcinogenicity testing in rats or mice is the standard method of the identification of chemical carcinogenicity. However, such tests are extremely time-consuming, laborious, and expensive. Therefore, a screening assay for the carcinogenicity of chemicals was established, and preneoplastic lesions were accepted as the endpoint markers of the assay (3).

In this article, we present data on the quantitative assessment of key carcinogenic events that are essential for the qualitative analysis of genotoxic carcinogenicity. We examined DNA adduct formation, oxidative stress, and gene mutation as the initiation events of hepatocarcinogenesis in rats. Furthermore, analyzed the number of glutathione $S$-transferase placental form (GST-P)-positive foci, which are the preneoplastic lesions, in rat liver (3), and evaluated cancer induction in long-term carcinogenicity studies.

\section{QUANTITATIVE ANALYSIS OF THE LOW-DOSE HEPATOCARCINOGENICITY OF 2-AMINO-3,8- DIMETHYLIMIDAZO(4,5-F)QUINOXALINE IN RAT LIVER}

2-Amino-3,8-dimethylimidazo-(4,5-f)quinoxaline (MeIQx) is a heterocyclic amine contained in seared fish and meat. MeIQx at 100 400 ppm administered via diet exerts carcinogenicity in rat liver $(4,5)$ and has been classified into Group 2B by the International Agency on Cancer Research (IARC) (6). To examine the carcinogenic events initiated by MeIQx at low doses in rat liver, a total of 1145 male F344 rats (aged 21 days) were fed a diet containing MeIQx at $0,0.001,0.01,0.1,1,10$ (low doses), and $100 \mathrm{ppm}$ (high dose) for 4-32 weeks (7). The number of MeIQxDNA adducts at week 4 was below the limit of detection in the 0 and $0.001 \mathrm{ppm}$ groups but was increased in the 0.01 100 ppm groups (Fig. 1). This increase was dose-

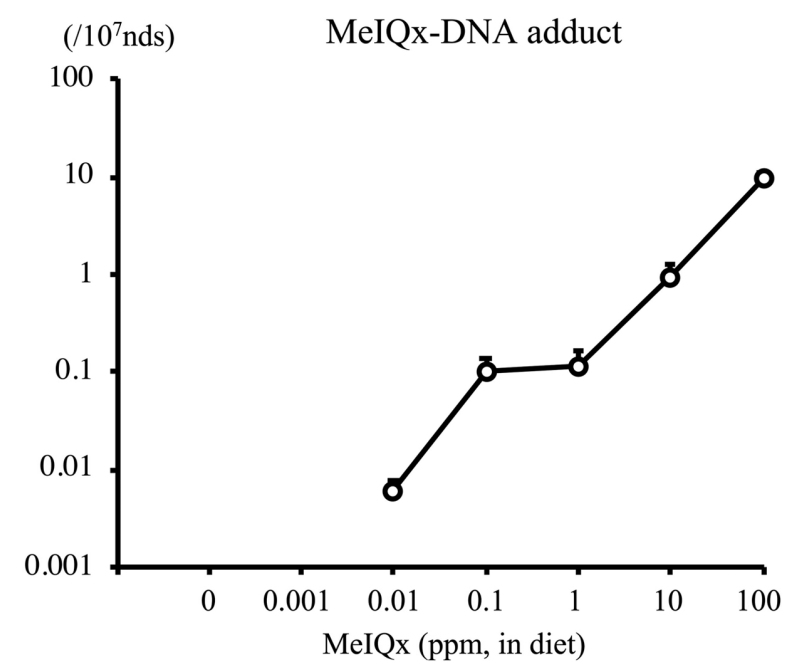

Fig. 1. MelQx-DNA adduct level in the liver of F344 rats treated with MelQx at various doses for 4 weeks (7). MelQx, 2-amino3,8-dimethylimidazo-(4,5-f)quinoxaline.

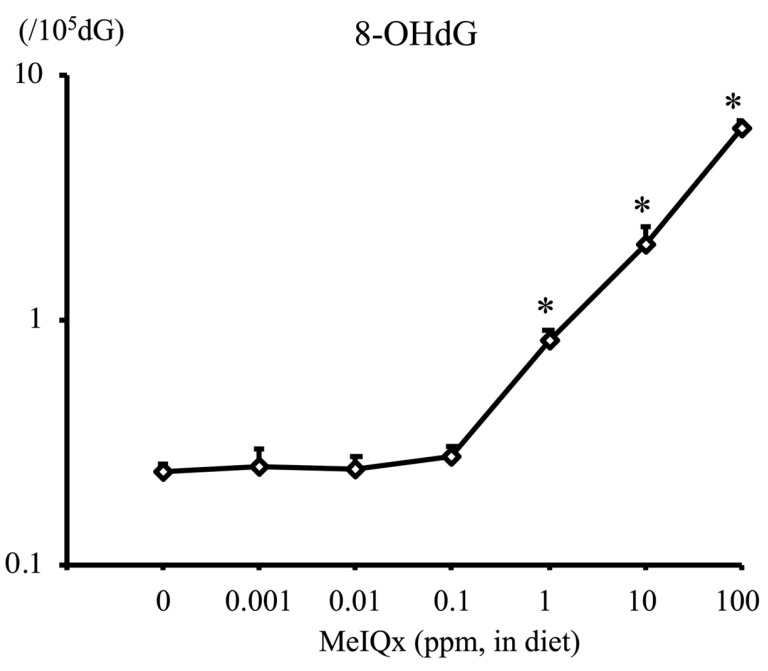

Fig. 2. 8-OHdG level in the liver of F344 rats treated with MelQx at various doses for 4 weeks. ${ }^{*} p<0.01$ versus $0 \mathrm{ppm}$ group (7). 8-OHdG, 8-hydroxy-2'-deoxyguanosine; MelQx, 2amino-3,8-dimethylimidazo-(4,5-f)quinoxaline. 


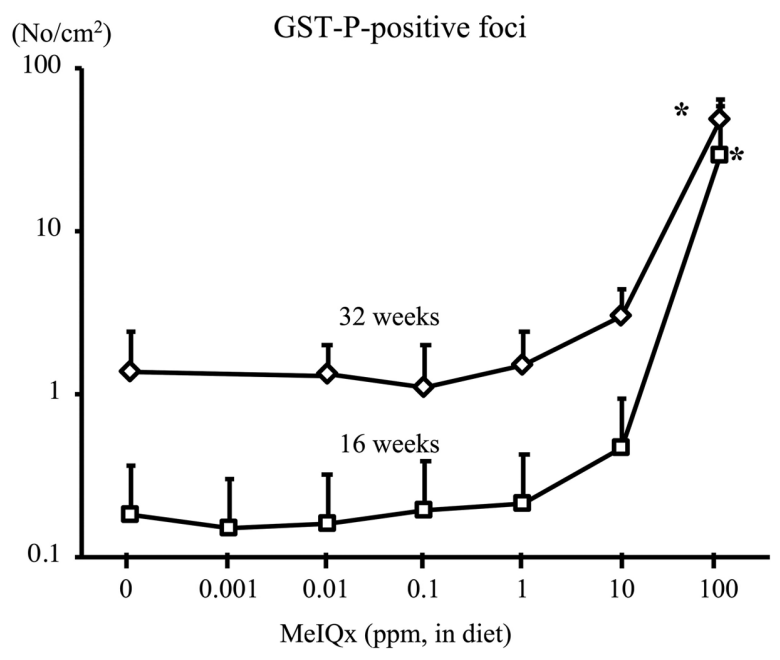

Fig. 3. GST-P positive foci in the liver of F344 rats treated with MelQx at various doses for 16 and 32 weeks. ${ }^{*} p<0.01$ versus respective $0 \mathrm{ppm}$ group (7). GST-P, glutathione $S$-transferase placental form; MelQx, 2-amino-3,8-dimethylimidazo$(4,5-f)$ quinoxaline.

dependent and significant in the $100 \mathrm{ppm}$ group. The increase in DNA adduct formation at week 16 was similar to that at week 4. Interestingly, MeIQx induced the generation of a marker of oxidative DNA damage, 8-hydroxy2'-deoxyguanosine $(8-\mathrm{OHdG})$, in rat liver. 8 -OHdG levels at week 4 were significantly higher in the liver of rats treated with MeIQx at 1, 10, and 100 ppm than in the control (Fig. 2). Similar results were obtained at week 16. The number of GST-P positive foci (foci with more than 2 cells) at week 16 was significantly increased in the $100 \mathrm{ppm}$ group (Fig. 3). The same results were obtained at 32 weeks.
In another study, lacI mutations in the liver of Big Blue ${ }^{\circledR}$ rats were examined (8). Forty male rats at 6 weeks of age were administered MeIQx at 0, 0.001, 0.01, 0.1, 1, 10 (low doses), and $100 \mathrm{ppm}$ (high dose) via their diet for 16 weeks. MeIQx at 10 and $100 \mathrm{ppm}$ significantly increased the frequency of lacI mutation in the rat livers (Fig. 4A). However, the significant increase in lacI mutation level was lower than that in GST-P positive foci (Fig. 4B).

Because lacI mutations in rat liver were increased by MeIQx administration, we subsequently evaluated the ability of MeIQx to initiate carcinogenesis in a 2-step carcinogenicity test where MeIQx treatment was followed by phenobarbital (PB), a typical promoter of hepatocarcinogenesis in rodents (9). Interestingly, the number of cells initiated by MeIQx was similar to the level of lacI mutation induced by MeIQx.

In a long-term carcinogenicity study, male F344 rats were administered MeIQx at 0, 1, 10, and $100 \mathrm{ppm}$ via their diet for 2 years (10). Only MeIQx at 100 ppm significantly induced hepatocellular adenoma $(27 \%)$ and carcinoma (12\%), and no liver tumor was observed at $0,0.1$, and $10 \mathrm{ppm}$ (10). Previously, Kushida et al. reported that MeIQx causes a dose-dependent elevation of hepatocellular adenoma and carcinoma in F344 rats administered MeIQx at 0, 100, 200, and 400 ppm for 56 weeks (5).

International Workshops on Genotoxicity Testing (IWGT) Working Group on Quantitative Approaches to Genetic Toxicology Risk Assessment (QWC) had discussed the existence of thresholds for the effects of genotoxic carcinogens (11) and concluded that it is not productive to debate the existence of thresholds for mutagenic and clastogenic agents. Instead, QWC emphasized the determination of point of departure (PoD), from which acceptable

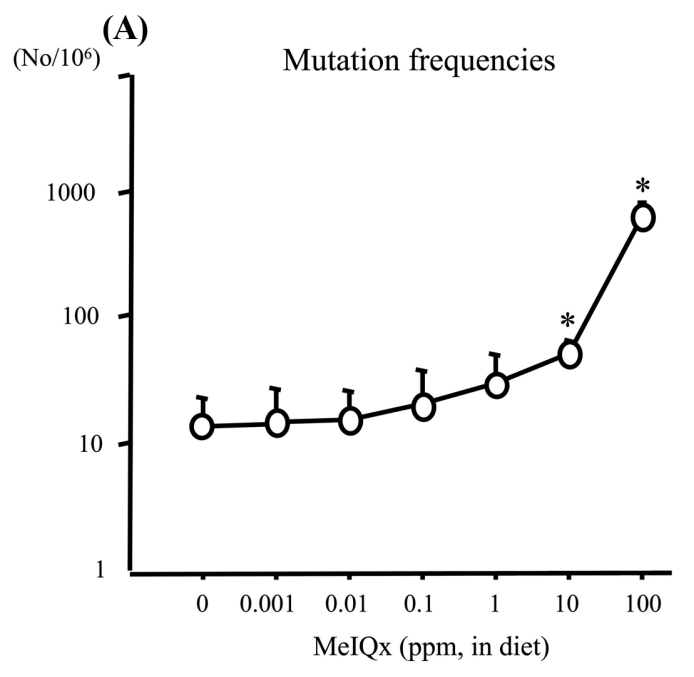

(B)

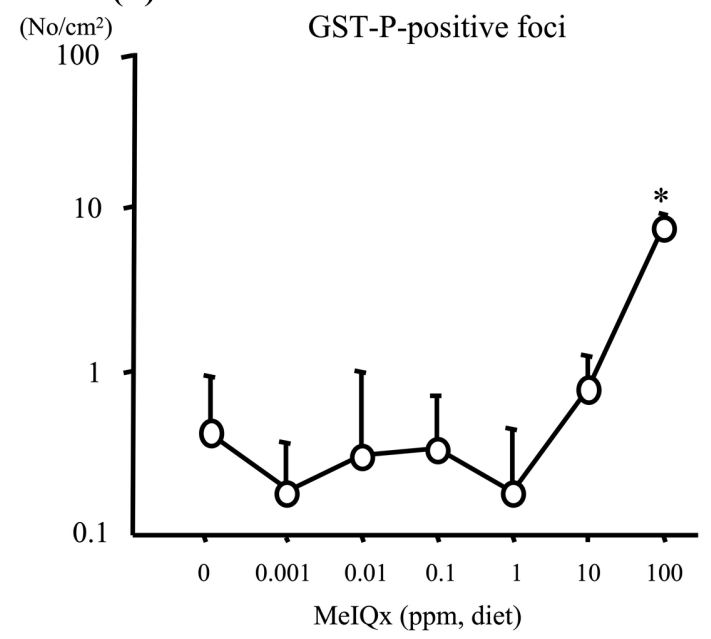

Fig. 4. lacl gene mutation frequencies (A) and GST-P positive foci (B) in the liver of Big Blue ${ }^{\circledR}$ rats treated with MelQx at various doses for 16 weeks. * $p<0.001$ versus 0 ppm group (8). GST-P, glutathione S-transferase placental form; MelQx, 2-amino-3,8-dimethylimidazo-(4,5-f)quinoxaline. 


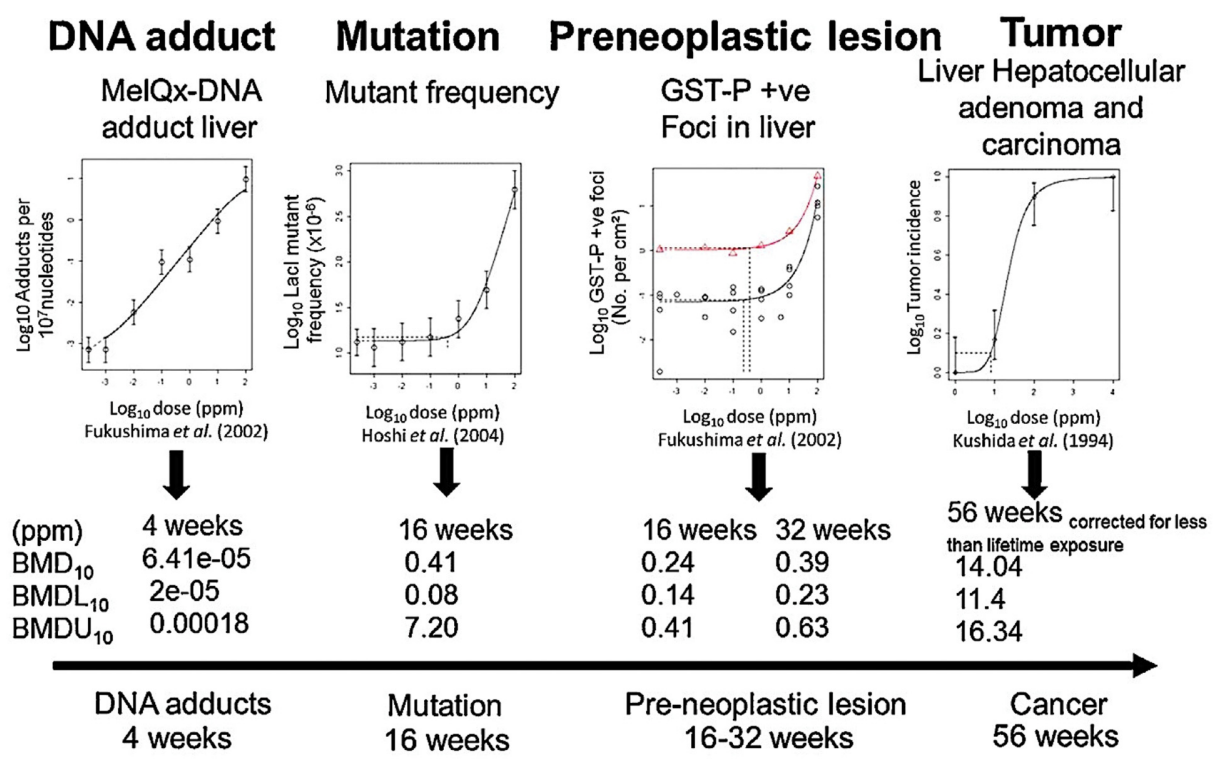

$\mathrm{BMDL}_{10}$ ranking:

DNA adduct ${ }_{4 \text { weeks }}<<$ Mutation $_{16 \text { weeks }}<$ Foci $_{16 \text { weeks }}<$ Foci $_{32 \text { weeks }}<$ Cancer $_{56 \text { weeks }}$

Fig. 5. Dose-response plots and derived $B M D L_{10}$ values for DNA adducts, mutations, GST-P positive foci, and hepatocellular adenoma and carcinoma in the liver of F344 rats treated with MelQx at various doses (12). BMDL 10 , lower $95 \%$ confidence limit of the benchmark dose corresponding to a 10\% extra risk; GST-P, glutathione S-transferase placental form; MelQx, 2-amino-3,8-dimethylimidazo-(4,5-f)quinoxaline.

exposure levels can be determined by extrapolation using available mechanistic information and uncertainty factors. Benchmark dose (BMD) was recommended as an approach to derive POD from raw data. QWC concluded that BMD modeling almost always yields a good fit to the data, whereas $\mathrm{BMDL}_{10}$ and $\mathrm{BMDL}_{1 \mathrm{SD}}$ values are more conservative and always essentially lower than the no-observedgenotoxic-effect level. Moreover, because it is important to predict carcinogenic risk and association of genetic damage, QWC used BMD to examine the quantitative correlations between early cancer-related genetic endpoints, preneoplasia, and cancer potency. QWC illustrated a case example using our data on MeIQx-induced carcinogenic events, such as elevation of DNA adducts, mutations, and preneoplastic lesions $(7,8)$, as well as development of liver tumor (5). In this case, as illustrated in Fig. 5, the genotoxic carcinogenesis pathway showed an expected trend where $\mathrm{BMDL}_{10} \mathrm{~s}$ was low in the early stages of carcinogenesis: DNA adduct $<<$ mutation $<$ GST-P positive foci $<$ cancer (12).

Research on the modifying factors of the low-dose carcinogenicity of genotoxic carcinogens is very important. Kang et al. (13) examined the low-dose carcinogenicity of MeIQx in rat liver damaged by thioacetamide (TAA), a well-known hepatotoxic chemical. After induction of liver fibrosis by TAA, MeIQx at various doses was administered to rats via their diet. A linear dose-dependent increase in the number of MeIQx-DNA adducts was virtually identi- fied in the damaged livers. A significant increase in the number of GST-P positive foci was observed only in the high-dose group (100 ppm), although it was higher in the TAA-treated group than in the control. In addition, in a low-dose carcinogenicity testing of MeIQx, the genetic influence of MeIQx was examined in male F344 and Brown Norway rats (14). No difference in the trend of GST-P positive foci induction by MeIQx was observed between both rat strains, although their values were different.

\section{QUANTITATIVE ANALYSIS OF THE LOW-DOSE HEPATOCARCINOGENICITY OF 2-AMINO-3- METHYLIMIDAZO(4,5-F)QUINOLINE IN RAT LIVER}

2-Amino-3-methylimidazo(4,5-f)quinoline (IQ) is another heterocyclic amine contained in seared fish and meat. It was reported that IQ at $300 \mathrm{ppm}$ administered via diet exerts carcinogenicity in rat liver (15). IQ has been classified into Group 2A by IARC (16).

To examine the carcinogenic effects of IQ at low doses in rat liver, a total of 1595 male F344 rats (aged 21 days) were administered IQ at doses of $0,0.001,0.01,0.1,1,10$ (low doses), and $100 \mathrm{ppm}$ (high dose) via their diet for 16 weeks (17). The number of IQ-DNA adducts at week 4 was below the limit of detection in the 0 and $0.001 \mathrm{ppm}$ groups but was increased by $0.01 \sim 100$ ppm IQ (Fig. 6) in 


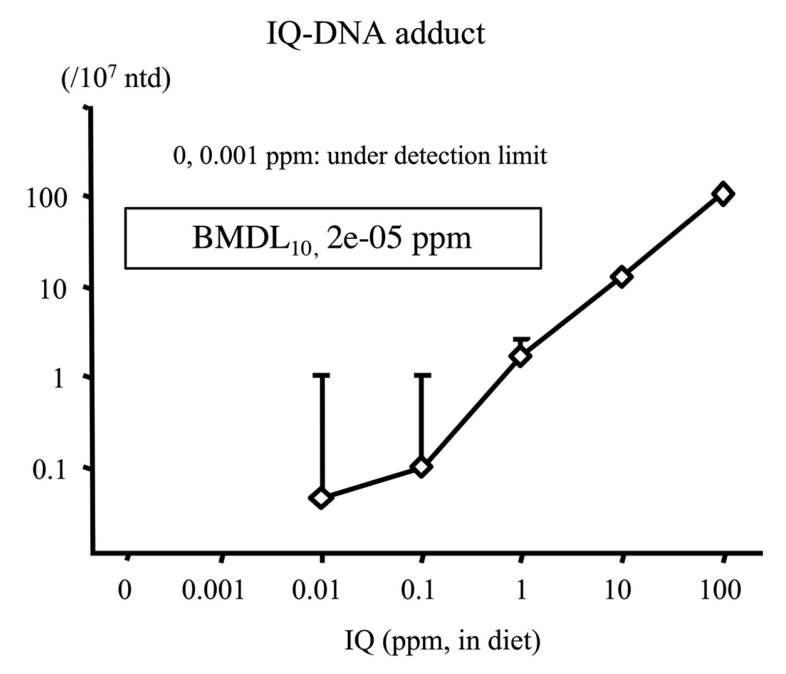

Fig. 6. IQ-DNA adduct formation in the liver of F344 rats treated with IQ at various doses for 16 weeks (17). IQ, 2-amino3-methylimidazo(4,5-f)quinoline.

a dose-dependent manner. The number of GST-P positive foci significantly increased in the liver of rats treated with IQ at 10 and 100 ppm for 16 weeks (Fig. 7). The BMDL was $2 \mathrm{e}-05$ and $1.4 \mathrm{ppm}$ for DNA-adduct and GST-P positive foci, respectively. Thus, similar to MeIQx data, IQDNA adduct formation was increased by IQ at very low doses, whereas the dose required to increase the number of GST-P positive foci was much higher. Dose levels of the IQ-induced mutations after 4 weeks of administration to gpt-delta rats were quite lower than that of GST-P positive foci but higher than DNA adduct formation level (unpublished data). Therefore, the ranking of PODs by

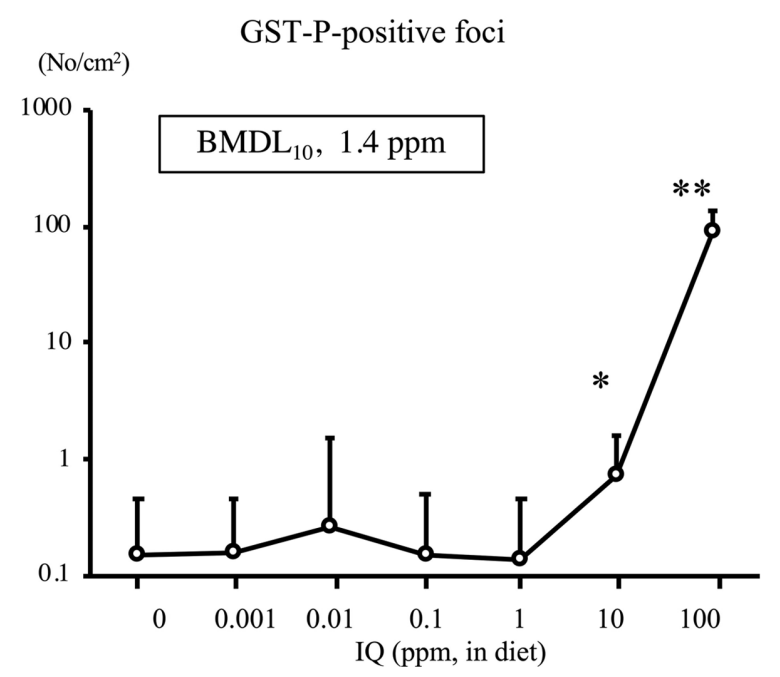

Fig. 7. GST-P positive foci in the liver of F344 rats treated with IQ at various doses for 16 weeks. ${ }^{*} p<0.01$ versus 0 ppm group. ${ }^{* *} p<0.001$ versus $0 \mathrm{ppm}$ group (17). GST-P, glutathione S-transferase placental form; IQ, 2-amino-3-methylimidazo(4,5f)quinoline.
BMDL $_{10}$ was DNA adduct $<$ mutation $<$ GST-P positive foci.

\section{CONCLUSIONS}

Ultimate carcinogens derived from genotoxic carcinogens bind covalently to DNA, forming DNA adducts that can interfere with normal DNA metabolism, leading to DNA mutations. Although most DNA adducts are efficiently repaired, there is a possibility of misrepair during the replication of damaged DNA, resulting in the fixation of a mutation. Most mutated cells will die because of metabolic dysfunctions or apoptosis; however, it is possible that some mutated cells survive and be viable. Cell proliferation enhances the ability of mutated (initiated) cells to form preneoplastic lesions and develop into benign and then malignant tumors. Carcinogenesis studies indicated that before developing into tumors, many preneoplastic lesions disappear or last continuously at that state.

Qualitative assessment based on carcinogenesis pathway is very important to extrapolate the results of genotoxic carcinogenicity studies in human, particularly those of low-dose carcinogenicity studies. Thus, quantitative assessment is conducted for each event of carcinogenesis in order to contribute to the analysis of low-dose carcinogenicity. To increase the weight of evidence in this assessment, PoD can be used to analyze the dose-response data of genotoxicity and carcinogenicity. The relationship between DNA adducts, mutation level, preneoplastic lesion, and tumors was derived from the low-dose carcinogenicity data of MeIQx and IQ and is summarized in Fig 8. PoDs vary for each qualitative marker of in vivo carcinogenicity mechanism, suggesting a need to reconsider the putative non-threshold theory of genotoxic carcinogens. The detailed contents of this article are presented elsewhere (18). In conclusion, our studies on the low-dose carcinogenicity of genotoxic chemicals indicates the existence of threshold, at least practical, for genotoxic carcinogenicity.

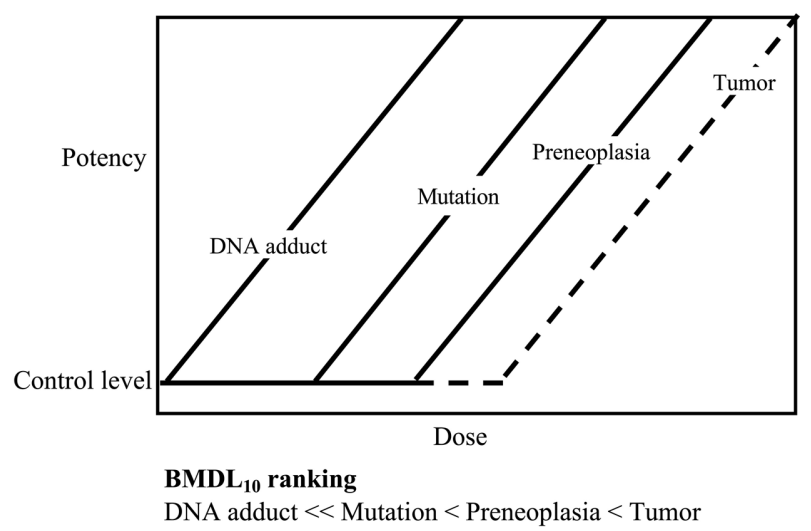

Fig. 8. Dose-response curves of genotoxic carcinogenesis events derived from $B M D L_{10}$, lower $95 \%$ confidence limit of the benchmark dose corresponding to a $10 \%$ extra risk. 


\section{ACKNOWLEDGMENTS}

This article describes the content of the 12th International Conference and 5th Asian Congress on Environmental Mutagens (ICEM-ACEM 2017) with the 33rd Annual Meeting of KSOT/KEMS in Incheon, Korea. We appreciate the organizing committee of ICEM-ACEM 2017 for giving us a chance to contribute this article.

\section{CONFLICT OF INTEREST}

There are no financial or other interests regarding the submitted manuscript that might be construed as a conflict of interest.

Received July 23, 2018; Revised August 20, 2018; Accepted August 30, 2018

\section{REFERENCES}

1. Farmer, J.H., Kodell, R.L., Greenman, D.L. and Shaw, G.W. (1980) Dose and time responses models for the incidence of bladder and liver neoplasms in mice fed 2-acetylaminofluorene continuously. J. Environ. Pathol. Toxicol., 3, 55-68.

2. Peto, R., Gray, R., Brantom, P. and Grasso, P. (1991) Effects on 4080 rats of chronic ingestion of $\mathrm{N}$-nitrosodiethylamine or N-nitrosodimethylamine: a detailed dose-response study. Cancer Res., 51, 6415-6451.

3. Ito, N., Tamano, S. and Shirai, T. (2003) A medium-term rat liver bioassay for rapid in vivo detection of carcinogenic potential of chemicals. Cancer Sci., 94, 3-8.

4. Kato, T., Ohgaki, H., Hasegawa, H., Sato, S., Takayama, S. and Sugimura, T. (1988) Carcinogenicity in rats of a mutagenic compound, 2-amino-3,8-dimethylimidazo[4,5-f]quinoxaline. Carcinogenesis, 9, 71-73.

5. Kushida, H., Wakabayashi, K., Sato, H., Katami, M., Kurosaka, R. and Nagao, M. (1994) Dose-response study of MeIQx carcinogenicity in F344 male rats. Cancer Lett., 83, 31-35.

6. IARC (1993) IARC monographs on the evaluation of carcinogenic risks to humans: Some nuturally occurring substances: food items and constituents, heterocylic aromatic amines and mycotoxins. MeIQx (2-amino-3,8-dimethylimidazo(4,5-f)quinoxaline), World Health Organization, International Agency for Research on Cancer, Lyon.

7. Fukushima, S., Wanibuchi, H., Morimura, K., Wei, M., Nakae, D., Konishi, Y., Tsuda, H., Uehara, N., Imaida, K., Shirai, T., Tatematsu, M., Tsukamoto, T., Hirose, M., Furukawa, F., Wakabayashi, K. and Totsuka, Y. (2002) Lack of a dose-response relationship for carcinogenicity in the rat liver with low doses of 2-amino-3,8-dimethylimidazo[4,5-f]quinoxaline or N-nitrosodiethylamine. Jpn J. Cancer Res., 93, 1076-1082.

8. Hoshi, M., Morimura, K., Wanibuchi, H., Wei, M., Okochi, E., Ushijima, T., Takaoka, K. and Fukushima, S. (2004) Noobserved effect levels for carcinogenicity and for in vivo mutagenicity of a genotoxic carcinogen. Toxicol. Sci., 81, 273-279.

9. Fukushima, S., Wanibuchi, H., Morimura, K., Wei, M., Nakae, D., Konishi, Y., Tsuda, H., Takasuka, N., Imaida, K., Shirai,
T., Tatematsu, M., Tsukamoto, T., Hirose, M. and Furukawa, F. (2003) Lack of initiation activity in rat liver of low doses of 2-amino-3,8-dimethylimidazo[4,5-f]quinoxaline. Cancer Lett., 191, 35-40.

10. Murai, T., Mori, S., Kang, J.S., Morimura, K., Wanibuchi, H., Totsuka, Y. and Fukushima, S. (2008) Evidence of a threshold-effect for 2-amino-3,8-dimethylimidazo-[4,5-f]quinoxaline liver carcinogenicity in F344/DuCrj rats. Toxicol. Pathol., 36, 472-477.

11. MacGregor, J.T., Frotschl, R., White, P.A., Crump, K.S., Eastmond, D.A., Fukushima, S., Guerard, M., Hayashi, M., Soeteman-Hernandez, L.G., Kasamatsu, T., Levy, D.D., Morita, T., Muller, L., Schoeny, R., Schuler, M.J., Thybaud, V. and Johnson, G.E. (2015) IWGT report on quantitative approaches to genotoxicity risk assessment I. Methods and metrics for defining exposure-response relationships and points of departure (PoDs). Mutat. Res. Genet. Toxicol. Environ. Mutagen., 783, 55-65.

12. MacGregor, J.T., Frotschl, R., White, P.A., Crump, K.S., Eastmond, D.A., Fukushima, S., Guerard, M., Hayashi, M., Soeteman-Hernandez, L.G., Johnson, G.E., Kasamatsu, T., Levy, D.D., Morita, T., Muller, L., Schoeny, R., Schuler, M.J. and Thybaud, V. (2015) IWGT report on quantitative approaches to genotoxicity risk assessment II. Use of pointof-departure (PoD) metrics in defining acceptable exposure limits and assessing human risk. Mutat. Res. Genet. Toxicol. Environ. Mutagen., 783, 66-78.

13. Kang, J.S., Wanibuchi, H., Morimura, K., Totsuka, Y., Yoshimura, I. and Fukushima, S. (2006) Existence of a no effect level for MeIQx hepatocarcinogenicity on a background of thioacetamide-induced liver damage in rats. Cancer Sci., 97, 453-458.

14. Wei, M., Hori, T.A., Ichihara, T., Wanibuchi, H., Morimura, K., Kang, J.S., Puatanachokchai, R. and Fukushima, S. (2006) Existence of no-observed effect levels for 2-amino-3,8dimethylimidazo[4,5-f]quinoxaline on hepatic preneoplastic lesion development in BN rats. Cancer Lett., 231, 304-308.

15. Ohgaki, H., Hasegawa, H., Kato, T., Suenaga, M., Ubukata, M., Sato, S., Takayama, S. and Sugimura, T. (1986) Carcinogenicity in mice and rats of heterocyclic amines in cooked foods. Environ. Health Perspect., 67, 129-134.

16. IARC (1993) IARC monographs on the evaluation of carcinogenic risks to humans: Some nuturally occurring substances: food items and constituents, heterocylic aromatic amines and mycotoxins. IQ (2-amino-3-methylimidazo(4,5f)quinoline), World Health Organization, International Agency for Research on Cancer, Lyon.

17. Wei, M., Wanibuchi, H., Nakae, D., Tsuda, H., Takahashi, S., Hirose, M., Totsuka, Y., Tatematsu, M. and Fukushima, S. (2011) Low-dose carcinogenicity of 2-amino-3-methylimidazo[4,5-f]quinoline in rats: Evidence for the existence of no-effect levels and a mechanism involving p21(Cip/WAF1). Cancer Sci., 102, 88-94.

18. Fukushima, S., Gi, M., Kakehashi, A. and Wanibuchi, H. (2016) Qualitative and quantitative assessment on low-dose carcinogenicity of genotoxic hepatocarcinogens: Dose-response for key events in rat hepatocarcinogenesis in Thresholds of Genotoxic Carcinogen (Nohmi, T. and Fukushima, S. Eds.). Academic Press, pp. 1-17. 